\title{
Antiemetic in Caesarean section under spinal anaesthesia: new option
}

\author{
Balaram Ghosh ${ }^{1}$, Suman Chattopadhyay ${ }^{2}$, Tapan Kr. Naskar ${ }^{3}$, \\ Biswanath Biswas ${ }^{4}$, Manasi Banerjee ${ }^{5}$, Mihir Sarkar ${ }^{6}$ \\ ${ }_{1,5}$ Assistant Professor, Dept. of Pharmacology, Medical College, Kolkata. \\ ${ }^{2}$ Associate Professor, Dept. of Anesthesiology, Medical College, Kolkata. \\ ${ }^{3}$ Associate Professor, Dept. of Obstetrics \& Gynecology, Medical College, Kolkata. \\ ${ }^{4}$ Professor of Anesthesiology, College of Medicine \& J.N.M. Hospital, Kalyani \\ ${ }^{6}$ Assistant Professor, Dept. of Obstetrics \& Gynaecology, Calcutta National Medical College, Kolkata
}

\begin{abstract}
Objective: Postoperative nausea and vomiting (PONV) after spinal anaesthesia for caesarean delivery are distressing to patients, anaeathesist and surgeon. This study was designed to evaluate the efficacy and safety of granisetron and ramosetron (both potent $5 \mathrm{HT}_{3}$ receptor antagonist) on the incidences of nausea and vomiting in caesarean delivery after spinal anaesthesia in India.

Place \& Duration of Study: The study was done at Eden Hospital, Medical College, Kolkata 700073, India for six months (November, 2011 to April, 2012).

Patients, Design \& Methods of Study: In this randomized, double-blind study, 120 parturients (60 in each group) received granisetron $(2 \mathrm{mg}$ in $2 \mathrm{ml}$ ) or ramosetron $(0.3 \mathrm{mg}$ in $2 \mathrm{ml}$ ) intravenously immediately after clamping of the foetal umbilical cord. Nausea, vomiting and adverse events were then observed for $48 \mathrm{~h}$ after administration of spinal anaesthesia.
\end{abstract}

Results: A complete response (defined as no postoperative nausea and vomiting) during first $0-2 \mathrm{~h}$ postoperative after administration of spinal anaesthesia was achieved in $83.3 \%$ of patients with granisetron and in $86 \%$ of patients with ramosetron. The corresponding incidence during 2 to $24 \mathrm{~h}$ was $85 \%$ and $88.3 \%$, while it was $70 \%$ and $91.6 \%$ at 24-48 h after anesthesia ( $p<0.05)$. At 24-48 h after anesthesia, nausea and vomiting were less severe in patients who received ramosetron than in those who received granisetron $(\mathrm{p}<$ $0.05)$. Patients who received ramosetron were also more satisfied than those who received granisetron ( $\mathrm{p}<$ 0.05). No difference in adverse events was observed in any of the groups.

Conclusion: Prophylactic therapy with ramosetron is more effective than prophylactic therapy with granisetron for the long-term prevention of PONV in caesarean section in India.

\section{Article Proper:}

Introduction: Postoperative nausea and vomiting (PONV) after spinal anaesthesia in caesarean delivery are common occurrences ${ }^{1}$ and reported incidences are quite high ${ }^{1-2}$. Furthermore, post-delivery PONV can complicate postoperative care in several ways - (i) aspiration of vomit, (ii) electrolyte disturbance and dehydration, (iii) delay of nutrition, fluid intake and oral drug therapy, and (iv) wound dehiscence. For PONV prevention, selective serotonin 5- hydroxytryptamine type $3\left(5-\mathrm{HT}_{3}\right)$ receptor antagonists are considered one of the first-line therapy because of their efficacy and fewer side-effects compared with other antiemetics ${ }^{3}$. Most research on the $5-\mathrm{HT}_{3}$ receptor antagonists has been on ondansetron, and its antiemetic efficacy has been well established in chemotherapy-induced emesis and the prevention and treatment of PONV. Granisetron is a selective $5-\mathrm{HT}_{3}$ receptor antagonist and has more potent and longer acting properties than ondansetron for the treatment of cisplatin-induced emesis ${ }^{4}$. Recently granisetron has been found to have a prophylactic antiemetic effect on PONV in patients undergoing surgery under general anaesthesia ${ }^{5}$. Ramosetron is another recently developed selective 5- $\mathrm{HT}_{3}$ receptor antagonist. It exhibits significantly greater binding affinity for 5$\mathrm{HT}_{3}$ receptors with a slower dissociation rate from receptor binding, resulting in more potent and longer receptor antagonizing effects compared with older $5-\mathrm{HT}_{3}$ receptor antagonists ${ }^{6,7}$. Ramosetron and granisetron are similar with respect to prevention of emesis, nausea or drug-related adverse events in acute cisplatin-induced emesis, though ramosetron had a longer duration of action ${ }^{8}$. So far there is limited data on either granisetron or ramosetron in the Indian context ${ }^{9}$, more so regarding their use for preventing PONV in caesarean delivery.

We hypothesized that ramosetron is more effective than granisetron for the long-term prevention of $\mathrm{PONV}^{7,10}$. To test this hypothesis, we designed this prospective, randomized, double-blinded trial to assess the efficacy and safety of granisetron and ramosetron for preventing PONV patients undergoing spinal anaesthesia for caesarean delivery. 
Methods: After ethical committee approval from Institutional Ethics Committee, Medical College, Kolkata and written informed consent, 120 women (ASA 1 and 2) aged between 22 and 35 yrs undergoing elective caesarean delivery were included in this study. Women who had a history of motion sickness, previous history of emesis in post delivery period, history of acid peptic diseases, body weight $>85 \mathrm{Kg}$ and those who had received antiemetic meditation $24 \mathrm{hr}$. before surgery or having any contraindication to regional anesthesia were excluded from this study.

All women were explained the procedure and were randomly allocated, using a random number table, to receive intravenously one of three treatment regimens: Group $\mathrm{G}($ no. $=60)$ received granisetron $2 \mathrm{ml}(2 \mathrm{mg})$, while Group R (no. $=60$ ) received ramosetron $(0.3 \mathrm{mg}$ ) in $2 \mathrm{ml}$. Study agents were administered intravenously immediately after clamping of the umbilical cord. Study medications were prepared by personnel not involved in this study in individual $5 \mathrm{ml}$ covered and coded syringes to ensure blinding to the anesthetists. Patients and investigators who collected post delivery data were blinded to the study drug administered. Each parturient were pre-loaded with $15 \mathrm{ml} / \mathrm{Kg}$ of lactated Ringer's solution before induction of spinal anaesthesia. Pulse rate, blood pressure, $\mathrm{SpO}_{2}$ of each parturient and foetal heart rate were recorded before spinal anaesthesia. Under all aseptic precaution, lumbar puncture was performed in sitting position through $\mathrm{L}_{3-4}$ inter-vertebral space using 25 gauge Whitacre type lumber puncture needle and $0.5 \%$ hyperbaric bupivacaine $2 \mathrm{ml}(10 \mathrm{mg})$ was injected. Women were then placed supine with a wedge under right hip for $15^{\circ}$ left uterine displacement. Oxygen $3 \mathrm{lit} / \mathrm{min}$ was administered via face mask. Patients were monitored during procedure by continuous ECG, NIBP and pulse oximetry. The decrease in systolic blood pressure > 20\% of baseline values and/or less than $80 \mathrm{~mm} \mathrm{Hg}$ immediately after spinal injection was treated with additional intravenous fluids and/or ephedrine $5-10 \mathrm{mg}$ intravenously, as indicated. Following conformation of spinal block by loss of sensation to cold and pinprick to $\mathrm{T}_{4-5}$ level, surgery was started. Syntocinon 10 units were administered through intravenous infusion at the time of umbilical cord clamping. Patients in each group were allowed to receive pethidine $0.5 \mathrm{mg} / \mathrm{kg}$ intravenously if required for pain relief after delivery of the baby due to uterus exteriorization and/ or peritoneum manipulation.

Nausea was defined as a subjectively unpleasant sensation associated with awareness of the urge to vomit; retching was defined as the laboured, spasmodic rhythmic contraction of the respiratory muscles without the expulsion of gastric contents. Vomiting was defined as the forceful expulsion of gastric contents from mouth $^{11}$. If two or more episodes of emesis occurred in each observation period, another rescue antiemetic (ondansetron $4 \mathrm{mg}$ ) was given intravenously. We made no distinction between vomiting and retching. All episodes of PONV (nausea, retching, and vomiting) were recorded by direct questioning by trained nurses blinded to the study group or by spontaneous complaint by the patients during three periods within the first $48 \mathrm{~h}$ after anesthesia: 0-2 $\mathrm{h}$ in the post-anesthetic care unit, 2-24 $\mathrm{h}$ in the postpartum ward and $24-48 \mathrm{~h}$ in the general ward. The details of adverse effects were recorded during study period by the attending anesthesiologist. Postoperative analgesia was provided with pethidine $1.5 \mathrm{mg} / \mathrm{Kg}$ administered intramuscularly. Patient satisfaction regarding their satisfaction to be free of nausea and vomiting were performed on a linear numerical scale ranging from 0 (complete dissatisfaction) to 10 (complete satisfaction) at the completion of the study.

Sample size was predetermined using a power analysis to achieve an $80 \%$ chance $(\beta=0.2)$ of detecting a $40 \%$ reduction in PONV from a basal incidence of $70 \%$ (from $70 \%$ to $42 \%$ ) with an assumed significance level of $\alpha=0.05 .{ }^{12} \mathrm{~A}$ calculated minimum sample size was 49 patients in each group. A larger number of patients were included to allow for possible incomplete data collection or patient dropout. Statistical analysis was performed using SPSS for Windows (version 14, SPSS Inc., Chicago, IL, USA). A one-way analysis of variance was used to compare the continuous variables among the groups. If a significant difference was noted, a Bonferroni multiple comparison test was used to determine intergroup differences. Categorical variables were analyzed using the $\chi^{2}$ test or Fisher's exact test, as appropriate. A $p$-value of $<0.05$ was considered statistically significant. Data are presented as mean (SD), numbers, ranges or percentages.

\section{Results}

Patient profile and information on the surgery and operative management were summarized in Table I and Table II. The treatment groups were comparable with regard to patient demographics and operative management. The incidence of a complete response (no PONV, no rescue) $0-2 \mathrm{~h}$ after anesthesia was $83.3 \%$ with granisetron and $86.6 \%$ with ramosetron; the corresponding incidence $2-24 \mathrm{~h}$ after anesthesia was $85 \%$ and $88.3 \%$; while the corresponding incidence $24-48 \mathrm{~h}$ after anesthesia was $70 \%$ and $91.6 \%$ respectively. Thus, a complete response $24-48 \mathrm{~h}$ after anesthesia was more frequent in patients who had received ramosetron than in those who had received granisetron $(p<0.05)$. At $24-48 \mathrm{~h}$ after anesthesia, incidences of nausea and vomiting were lesser in patients who received ramosetron than in those who received granisetron $(p<0.05)$. Patients who received ramosetron were also more satisfied than those who received granisetron $(p<0.05) \quad$ (Table III).

Observed adverse events were headache, dizziness, constipation and myalgia which were not clinically serious. No difference in the incidence of adverse effects was observed between the groups as shown in Table IV \& Fig I. 


\section{Discussion}

Nausea and vomiting during regional anaesthesia for caesarean section is relatively high ${ }^{1}$ without prophylactic antimetic ${ }^{2}$. The aetiology of emetic symptoms following regional anaesthesia for caesarean delivery is complex and depends on a variety of factors including maternal demographics, operative procedure, the occurrence of postoperative pain, use of perioperative opioids, and anaesthetic techniques ${ }^{11}$, peritoneal traction ${ }^{12}$ and exteriorisation of uterus ${ }^{13}$. Maternal hypotension ${ }^{13}$ after induction of spinal anaesthesia is related to an increased incidence of intraoperative, post-delivery emetic episodes. This hypotension may trigger the vomiting centre to induce emesis due to hypoxia ${ }^{13,14}$. In this study pre-loading, left uterine displacement, supplementation of oxygen and administration of incremental doses of ephedrine were performed for the prevention and early treatment of their hypotension. Also the hypotension following spinal anaesthesia and requirement of ephedrine were more or less similar in both groups. In addition, patients in each group consumed similar amounts of pethidine as analgesic in the postoperative period. In our study as the treatment groups were similar with regard to maternal characteristics and operative management, we inferred that the differences in the incidence of PONV among the groups can be attributed to the study drug.

The exact mechanism of granisetron and ramosetron in the prevention of PONV is unknown, but these drugs may act by potently blocking $5-\mathrm{HT}_{3}$ receptors sites at area postrema and the nucleus tractus solitarius ${ }^{14}$. The dose of granisetron $2 \mathrm{mg}$ (approximately $40 \mu \mathrm{g} / \mathrm{Kg}$ ) used in this study was based on the report published by Fujii et $\mathrm{al}^{15}$, as well as a previous study done in the Indian contex $\mathrm{t}^{16}$. The dose of ramosetron in our study $(300 \mu \mathrm{g})$ was based on previous studies ${ }^{17}$.

We could not find any report to compare the efficacy of granisetron and ramosetron for preventing PONV in caesarean section. Our results demonstrate that the antiemetic efficacy of ramosetron is similar to that of granisetron for preventing PONV during the first 24 hours (0-24 hours) after anesthesia and that ramosetron is more effective than granisetron for increasing a complete response (no PONV, no rescue) within the next 24 hours (24-48 hours). This is similar to a study done to compare these drugs in abdominal procedures ${ }^{18}$. This suggests that ramosetron has a more potent antiemetic effect that lasts up to 24 hours longer than granisetron. The exact reason for the difference in effectiveness between granisetron and ramosetron is not known but may be related to the elimination half-life (granisetron $3.1 \pm 1.2$ hours versus ramosetron $5.8 \pm 1.2$ hours) and/or more potent affinities of $5-\mathrm{HT}_{3}$ receptor antagonists ${ }^{19}$.

Our study could be criticized because we use opioid analgesia (pethidine) perioperatively, a recognized cause of $\mathrm{PONV}^{20}$. But there is an association between pain and $\mathrm{PONV}^{10,21}$, and treating pain with opioids may relieve PONV. ${ }^{21,22}$ Both granisetron and ramosetron are much more expensive than other available antiemetics in our set up. However, we should also consider the outcome of the patients and overall cost of care if emesis was to occur, as single doses of both granisetron and ramosetron are effective for $24 \mathrm{hr}$ or more.

In conclusion, prophylactic therapy with granisetron and ramosetron were both effective and comparable for prevention of post delivery emesis in the first $24 \mathrm{~h}$, but ramosetron is a better prophylactic for PONV after $24 \mathrm{hr}$, leading to overall better patient satisfaction.

\section{References}

[1] Santos A, Dutta S. Prophylactic use of droperidol for control of nausea and vomiting during spinal anaesthesia for caesarean section. Anesth Analg 1984; 63 : 85-7.

[2] Lussos S, BaderA, Thornhill M, Datta S. The anti-emetic efficacy and safety of prophylactic metoclopramide for elective caesarean delivery during spinal anaesthesia. Reg. Anaesthesia 1992; 17: 126-130.

[3] Habib AS, Gan TJ. Evidence-based management of postoperative nausea and vomiting: a review. Can J Anaesth 2004 ; 51: 326-41.

[4] Fujii Y, Saitoh Y, Tanaka H and Toyooka H. Granisetron/dexamethasone combination for the prevention of postoperative nausea and vomiting after laparoscopic cholecystectomy. Eur J Anaesthesiol 2000; 17 : 64-68.

[5] Janknegt R. Double-blind comparative study of droperidol, granisetron and granisetron plus dexamethasone as prophylactic antiemetic therapy in patients undergoing abdominal, gynaecological, breast or otolaryngological surgery. Anaesthesia 1999; 54 : 105968.

[6] Rabasseda X. Ramosetron, a 5-HT 3 receptor antagonist for the control of nausea and vomiting. Drugs Today $2002 ; 38: 75-89$.

[7] Akuzawa S, Ito H, Yamaguchi T. Comparative study of ramosetron and granisetron binding in the cloned human 5hydroxytryptamine 3 receptors. Jpn J Pharmacol 1998; 78: 381-4.

[8] Feng FY, Zhang P, He HJ, Li YH, Zhou MZ, Cheng G, Yamamoto M. Comparison of the selective serotonin 3 antagonists ramosetron and granisetron in treating acute chemotherapy-induced emesis, nausea, and anorexia: a single-blind, randomized, crossover study. Current Therapeutic Research 2000: 61: 901-9.

[9] Gautam PL, Kaul TK. PONV- An unsolved problem : Editotial J Anaesthesaiology Clinical Pharmacology $2002 ; 18$ : 3-4.

[10] Fujii Y, Tanaka H. Comparison of granisetron and ramosetron for the prevention of nausea and vomiting after thyroidectomy. Clin Ther 2002; 24:766-72.

[11] Watcha MF, White PF. Post-operative nausea and vomiting : Its etiology, treatment and prevention. Anaesthesiology 1992 ; 77 : $162-84$.

[12] Naguib M, elBakry AK, Khoshim MH. Prophylactic antiemetic therapy with ondansetron, tropisetron, granisetron and metoclopramide in patients undergoing laparoscopic cholecystectomy: a randomized, double-blind comparison with placebo. Can J Anaesth 1996; 43: 226-31. 
[13] Manullang TR, Viscomi CM, Pace NL. Intrathecal fentanyl is superior to intravenous ondansetron for the prevention of perioperative nausea during caesarean delivery with spinal anaesthesia. Anaesth Analg 2000; 90 : 1162-66.

[14] Brunton LL, Parker KL, editors. Goodman and Gilman's Manual of Pharmacology and Therauptics 2008, Mc Graw-Hill : New Delhi; pp 635-52. (DOI: 10.1036/ 0071443436)

[15] Fujii Y, Tanaka H, Toyooka H. Granisetron prevents nausea and vomiting during spinal anaesthesia for caesarean section. Acta Anaesthesiol Scand 1998; $42: 312-5$.

[16] Bhattacharya D, Banerjee A. Comparison of ondansetron and granisetron for prevention of nausea and vomiting following Day care gynaecological laparoscopy. Indian J. Anaesth. 2003; 47 (4) : 279-82

[17] Fujii Y, Saitoh Y, Tanaka H, Toyooka H. Ramosetron for preventing postoperative nausea and vomiting in women undergoing gynecological surgery. Anesth Analg 2000; $90: 472-5$

[18] Fujii Y, Saitoh Y, Tanaka H, Toyooka H. Ramosetron vs granisetron for the prevention of postoperative nausea and vomiting after laparoscopic cholecystectomy. Can J Anaesth 1999; 46: 991-3

[19] Kawabata Y, Sakiyama H, Muto S, et al. Clinical evaluation and pharmacokinetics of ramosetron against the nausea and vomiting induced by anticancer drugs. Nishinihon J Urol 1994; 56: 1445-56.

[20] Kenny GNC. Risk factors for post-operative nausea and vomiting, Anesthesia 1994; 49 (Suppl.): 6-10.

[21] Anderson R, Krohg K. Pain as a major cause of postoperative nausea. Canadian Anaesthetists' Society Journal 1976; 23: 336-9.

[22] Jacobsson J, Davidson S, Andreen M, Westgreen M. Opioid supplementation to propofol anaesthesia for outpatient abortion a comparison between alfentanil, fentanyl and placebo. Acta Anaesthesiol Scand. 1991; 35 : 767-70.

\section{Table I: Maternal Demographics}

\begin{tabular}{llll} 
& & Table I: & Maternal Demographics \\
\cline { 3 - 4 } & & $\begin{array}{l}\text { Granisetron } \\
(\mathbf{n = 6 0})\end{array}$ & $\begin{array}{l}\text { Ramosetron } \\
(\mathbf{n = 6 0})\end{array}$ \\
Age (years) & & $25.7 \pm 3.5$ & $26 \pm 4.1$ \\
Weight (Kg) & & $56.8 \pm 7.2$ & $57.1 \pm 7.7$ \\
Multipara (no.) & 1 & 22 & 22 \\
& 51 & 49 \\
ASAGrade & 2 & 9 & 11 \\
Baseline systolic blood pressure & $124.6 \pm 8.1$ & $127.5 \pm 7.7$
\end{tabular}

[No significant difference]

Table II: Operative Management

\begin{tabular}{|c|c|c|}
\hline & $\begin{array}{l}\text { Granisetron } \\
(\mathbf{n}=60)\end{array}$ & $\begin{array}{l}\text { Ramosetron } \\
(\mathbf{n}=\mathbf{6 0})\end{array}$ \\
\hline Duration of Surgery (min) & $48.2 \pm 8.1$ & $49.1 \pm 7.6$ \\
\hline Uterus exteriorised (no.) & 56 & 55 \\
\hline $\begin{array}{l}\text { Duration of uterus exteriorized } \\
\text { (min) }\end{array}$ & $18.1 \pm 5.4$ & $18.5 \pm 6.7$ \\
\hline Total ephedrine (mg) & $6.5(0-10)$ & $7(0-10)$ \\
\hline $\begin{array}{l}\text { No. of patients receiving } \\
\text { intraoperative pethidine }\end{array}$ & 18 & 17 \\
\hline $\begin{array}{ll}\text { Intraoperative } & \text { pethidine } \\
\text { consumption }(\mathrm{mg}) & \end{array}$ & $27 \pm 4.1(25-50)$ & $26.9 \pm 4.1(25-50)$ \\
\hline Postoperative & $230.5(180-360)$ & $228.9(180-360)$ \\
\hline
\end{tabular}

consumption (mg)

Figures in ( ) indicate ranges

[No significant difference]

Table III: Number (\%) of patients having complete response (i.e. no PONV), nausea, vomiting during initial $2 \mathrm{~h}(0-2 \mathrm{~h})$ and the next $46 \mathrm{~h}(4-24 \mathrm{~h}$ and $24-48 \mathrm{~h})$ after administration of spinal anaesthesia

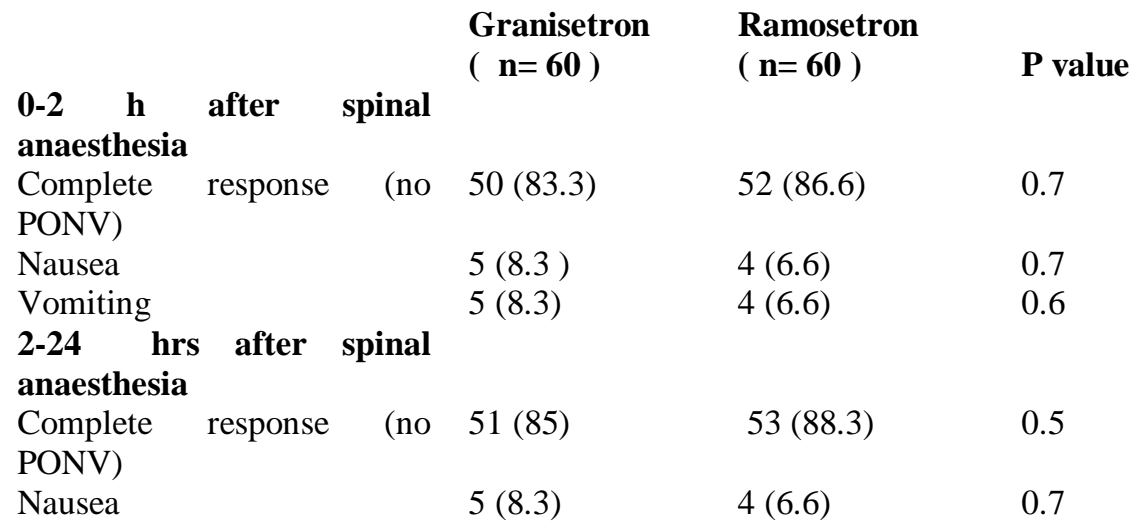


Vomiting
$\mathbf{2 4}-\mathbf{- 4 8}$ hrs after spinal

anaesthesia

Complete response (no $42(70) \quad 55(91.6) \quad 0.004^{*}$

PONV)

Nausea

Vomiting

$4(6.6)$

$3(5)$

0.7

Overall Satisfaction

$10(16.6)$

8 (13.3)

$3(5)$

$0.04 *$

$2(3.3)$

$0.02 *$

27 (45)

45 (75)

$0.031 *$

$* \mathbf{p}<0.05$

Table IV : Adverse effects

0-4 $\mathrm{h}$ after spinal anaesthesia

Headache

Dizziness

Constipation

Myalgia

4-24 hrs after spinal anaesthesia

Headache

Dizziness

Constipation

Myalgia

$\mathbf{2 4}-\mathbf{4 8} \mathrm{hrs}$ after spinal anaesthesia

Headache

Dizziness

Constipation

Myalgia

Granisetron( $n=60$ )

Ramosetron ( $n=60)$

$\begin{array}{ll}8(13.3 \%) & 7(11.6 \%) \\ 5(8.3 \%) & 3(5 \%) \\ 2(3.3 \%) & 2(3.3 \%) \\ 1(1.6 \%) & 1(1.6 \%) \\ & \\ 7(11.6 \%) & 8(13.3 \%) \\ 3(5 \%) & 3(5 \%) \\ 2(3.3 \%) & 2(3.3 \%) \\ 0 & 0 \\ 6(10 \%) & 5(8.3 \%) \\ 3(5 \%) & 3(5 \%) \\ 4(6.6 \%) & 4(6.6 \%) \\ 0 & 0\end{array}$

Fig: I.

NUMBER (\%) OF PATIENTS HAVING COMPLETE RESPONSE (NO PONV), NAUSEA, VOMITING IN DIFFERENT TIME.

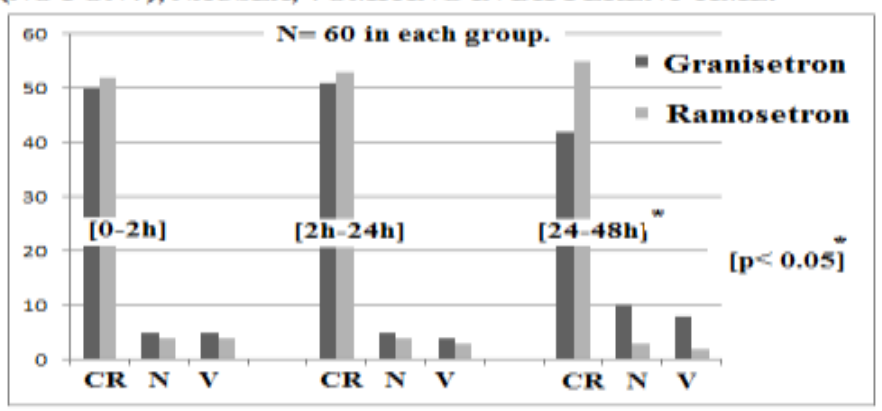

